\title{
Genetic Predisposition to Familial Nonmedullary Thyroid Cancer: An Update of Molecular Findings and State-of-the-Art Studies
}

\author{
Elena Bonora, ${ }^{1}$ Giovanni Tallini, ${ }^{2}$ and Giovanni Romeo ${ }^{1}$ \\ ${ }^{1}$ Unit of Medical Genetics, S.Orsola-Malpighi Hospital, 40138 Bologna, Italy \\ ${ }^{2}$ Dipartimento di Anatomia Patologica, Bellaria Hospital, University of Bologna, 40138 Bologna, Italy
}

Correspondence should be addressed to Giovanni Romeo, romeo@eurogene.org

Received 27 August 2009; Revised 9 February 2010; Accepted 1 April 2010

Academic Editor: Steven K. Libutti

Copyright (C) 2010 Elena Bonora et al. This is an open access article distributed under the Creative Commons Attribution License, which permits unrestricted use, distribution, and reproduction in any medium, provided the original work is properly cited.

\begin{abstract}
Familial thyroid cancer has become a well-recognized entity in patients with thyroid cancer originating from follicular cells, that is, nonmedullary thyroid carcinoma. The diagnosis of familial thyroid cancer provides an opportunity for early detection and possible prevention in family members. Understanding the syndromes associated with familial thyroid cancer allows clinicians to evaluate and treat patients for coexisting pathologic conditions. About five percents of patients with well-differentiated thyroid carcinoma have a familial disease. Patients with familial non-medullalry thyroid cancer have more aggressive tumors with increased rates of extrathyroid extension, lymph node metastases, and frequently show the phenomenon of "anticipation" (earlier age at disease onset and increased severity in successive generations). So far, four predisposition loci have been identified in relatively rare extended pedigrees, and association studies have identified multiple predisposing variants for differentiated thyroid cancer. This suggests that there is a high degree of genetic heterogeneity and that the development of this type of tumor is a multifactorial and complex process in which predisposing genetic variants interact with a number of incompletely understood environmental risk factors. Thus, the search for the causative variants is still open and will surely benefit from the new technological approaches that have been developed in recent years.
\end{abstract}

\section{Thyroid Cancer: Epidemiology and Clinicopathologic Features}

Thyroid cancer is divided into two types, based on the cells of origin: differentiated thyroid cancer of follicular cell origin (NMTC) and medullary thyroid cancer (MTC) originating from parafollicular cells [1]. The molecular mechanisms underlying MTC development, mainly due to gain-of-function mutations of the proto-oncogene RET have been studied in depth and are out of the scope of this work. Readers are referred to [2] for an updated review of the subject. Thyroid cancer is the most common form of neoplasia of the endocrine system, accounting for about $1 \%-3 \%$ of all cancers, with an annual incidence in various parts of the world ranging from 0.5-10 per 100000 [3]. The incidence of thyroid cancer is increasing, with one of the fastest rates of increase among common human cancers. Today, non-medullary thyroid cancer is the seventh most common tumor in women [4]. Improvement in cancer diagnosis can partly explain the phenomenon. However, early diagnosis alone is unlikely to account for this increase, and environmental factors must also play a role [5]. Several risk factors have been identified for thyroid carcinoma, such as radiation exposure, iodine deficiency and excess, and previous history of benign thyroid disease, such as nodules and autoimmune thyroid diseases. NMTC also has a significant gender bias, with a ratio of affected women : men of $2.6: 1$ [6], suggesting that the hormonal environment may play an important role. The vast majority of patients with sporadic NMTC have well-differentiated tumors, papillarythyroid carcinoma (PTC), or follicular thyroid carcinoma (FTC). Papillary thyroid carcinoma accounts for approximately $80 \%$ of NMTC and is characterized by distinctive nuclear alterations including pseudoinclusions, grooves, and chromatin clearing.PTCs smaller than $1 \mathrm{~cm}$ are referred to as papillary microcarcinomas [7]. These tumors have been identified in 
TABLE 1: Familial syndromes with associated non-medullary thyroid cancer.

\begin{tabular}{lllc}
\hline Syndrome & Clinical Features & Inheritance pattern & Locus \\
\hline $\begin{array}{l}\text { Gardner's } \\
\text { syndrome (FAP) }\end{array}$ & $\begin{array}{l}\text { gastrointestinal adenomatous polyps, } \\
\text { osteomas, epidermoid cysts, hypertrophy } \\
\text { of the retinal epithelium, desmoid } \\
\text { tumors, PTC (cribiform-morular variant) }\end{array}$ & Autosomal dominant & 5q21 \\
\hline Cowden disease & hamartoma, breast cancer, PTC, FTC & Autosomal dominant & 10q22 \\
\hline $\begin{array}{l}\text { Carney complex } \\
\text { pituitary, gonadal, and adrenal gland } \\
\text { cancer, PTC, FTC }\end{array}$ & Autosomal dominant & 17q23-24 \\
\hline syndrome & $\begin{array}{l}\text { Premature aging, soft tissue sarcomas, } \\
\text { osteosarcoma, FTC/PTC }\end{array}$ & Autosomal recessive & 8p11-p12 \\
\hline
\end{tabular}

up to $35 \%$ of individuals at autopsy, suggesting that they may be extremely common, although they rarely become clinically relevant. PTC can be also multifocal but is typically slow growing, with a tendency to spread to lymph nodes and usually has an excellent prognosis. Activation of the mitogenactivated protein kinase (MAPK) pathway as a result of mutually exclusive BRAF or RAS mutations or of somatic recombination of RET (RET/PTC rearrangement) or NTRK1 (TRK rearrangement) genes is found in the majority of PTCs [8, 9]. Follicular thyroid carcinoma accounts for approximately $15 \%$ of NMTC and is defined by its invasive features that result in infiltration of blood vessels and/or full penetration of the tumor capsule, in the absence of the nuclear alterations of papillary carcinoma. FTC is rarely multifocal does not usually metastasize to the regional lymph nodes but tends to spread via the bloodstream to the lung and bones. An important histologic variant of FTC is the oncocytic (Hürthle cell, oxyphilic) follicular carcinoma composed of eosinophilic cells repleted with mitochondria. Activating mutations of RAS genes, activation of the PTEN/AKT pathway (due to activating mutations of PIK3CA or loss-offunction mutations of PTEN) $[10,11]$, or rearrangements of the genes PAX8 and PPAR yon chromosome 2q24 are often found in sporadic FTC [12]. The least common form of NMTC, accounting for less than $5 \%$ of cases, is poorly differentiated and anaplastic (undifferentiated) thyroid carcinomas, the latter representing one of the most lethal forms of human tumors. Mutations in the tumor suppressor gene p53 are typically identified in this type of carcinoma [13].

\section{Familial Syndromes}

Several syndromes are associated with non-medullary thyroid cancer such as Gardner's syndrome (familial adenomatous polyposis, FAP), Cowden disease (multiple hamartoma), Carney complex, and Werner syndrome. A summary of the clinical features and genes involved (when known) in familial syndromes associated with thyroid cancer is reported in Table 1 [14]. Gardner's syndrome or FAP results from loss-of-function mutations in the APC (adenomatous polyposis coli) tumor-suppressor gene on chromosome 5 q21 and is associated with gastrointestinal adenomatous polyps, osteomas, epidermoid cysts, congenital hypertrophy of the retinal epithelium, desmoid tumors, and thyroid cancer. FAP is associated with a "cribiform-morular variant" of PTC, so called because of its unique histopathologic features. However, fewer than $2 \%$ of patients with FAP develop PTC, suggesting that PTC development is probably related to increased susceptibility rather than a specific mutation. Cowden disease, also known as "multiple hamartoma syndrome," is associated with an increased risk of developing both benign and malignant breast tumors, and well-differentiated thyroid tumors. Eighty percent of patients have germline mutations of the PTEN (phosphatase and tensin homologue) tumor-suppressor gene. Carney complex involves both endocrine and nonendocrine organs and can affect pituitary, thyroid, gonadal, and adrenal glands. Both PTC and FTC have been associated with Carney complex type 1 . The adrenal gland pathology includes a primary pigmented micronodular hyperplasia, which is the only known familial cause of adrenal Cushing's syndrome, and additional pathologies include myxomas, nevi, and schwannomas. Carney complex type 1 is associated with a mutation in the PPRKAR $1 \alpha$ (protein kinase A regulatory subunit type 1-alpha) gene. Werner syndrome is a disease of connective tissue characterized by premature aging and is often referred to as "progeria." Patients have a predisposition to cancer, notably soft tissue sarcomas, osteosarcoma, and thyroid cancer (FTC and also PTC) which may develop as the result of genomic instability. Mutations in the RecQ helicase WRN gene have been identified, but the exact role of WRN is not known. It is possible that RecQ helicase acts as a tumor suppressor and may be responsible for genome stability.

\section{Familial Nonmedullary Thyroid Carcinoma (FNMTC): Risk Factors and Genetic Predisposition}

Patients with familial NMTC may have more aggressive tumors with increased rates of extrathyroid extension, lymph node metastases, and larger tumors in younger patients [4], underscoring the importance of accurate diagnosis. Establishing the diagnosis of a familial thyroid carcinoma may provide the opportunity for its early identification and possible prevention in family members. About 5\% of patients who have well-differentiated thyroid carcinoma show a familial occurrence. The clinico-pathological features included in the analysis on familial NMTC are as reported in [15]; the mean tumor size in familial PTC/FTC is $\sim 1.7 \mathrm{~cm}$ 
diameter. When the primary cancer site is considered in epidemiological studies, the thyroid gland shows the highest estimate of familial relative risk among all organs (between 5 and 10.4 folds as compared to $\sim 1.8$ and 2.7 for breast and colon cancer, resp., [16]). This indicates the presence of a strongly inherited component of the disease $[6,16,17]$. As for all diseases, the identification of a relevant familial recurrence risk in NMTC is complicated by the argument that families share the same environment as well as a common genetic background and it is therefore difficult to distinguish between environmental and genetic contributing factors. Although the initial familial aggregations reported over a period of time were seen as chance occurrences due to a shared environment, familial occurrence has more recently been recognized as a significant risk factor in NMTC [18]. Since the first observation of a familial case of PTC by Robinson and Orr [19] who reported PTC in twins, a number of pedigrees have been identified. It has been estimated that a family with three affected members with clinical NMTC due to environmental causes would occur by chance less than once in every 100 years. Therefore, the existence of pedigree collections of the size presented by Lesueur et al. [20] cannot occur by chance, but rather are associated with inherited predisposition. Similarly, Malchoff et al., who presented a large pedigree with PTC with 5 clinically significant cases, noted that the chance of 5 PTC occurring in a family of 23 individuals by chance would be 1 in two billion [21]. A population-based study in Norway of 5673 patients who had a first-degree relative with an index thyroid cancer, confirmed that these patients had an increased risk of developing thyroid cancer [22]. The incidence of PTC, primary pigmented nodular adrenocortical disease, and its associated conditions increased sixfold in men and fourfold in women if a first-degree relative had NMTC. Patients who have two first degree relatives with well-differentiated thyroid cancer and do not have a familial syndrome are currently classified as having familial NMTC [23]. Those who have more than two direct relatives with FNMTC have a decreased survival compared with patients who have one or two affected direct relatives [14]. In order to differentiate between FNMTC and familial syndromes associated with thyroid cancer, it is important to detect extra-thyroidal disease in patients affected with a familial syndrome. Patients who have familial NMTC have more aggressive tumors with increased rates of extra-thyroid extension, lymph node metastases, and larger tumors in younger patients. A recent work by Capezzone et al. compared the features of patients with sporadic and familial NMTC patients and tested whether FNMTC patients with parent-child relationship exhibit an "anticipation" phenomenon (earlier age at disease onset and increased severity in successive generations) [15]. In fact, significant differences between sporadic PTC and FNMTC patients included more frequent tumor multifocality $(P=$ $.001)$ and worse final outcome in FNMTC patients $(P=$ .001). In addition, among FNMTC cases with parent-child relationships, an earlier age at disease presentation $(P<$ $.0001)$, diagnosis $(P<.0001)$, and disease onset $(P=.04)$ were found in the second generation when compared with the first generation. Patients in the second generation had a higher rate of lymph node metastases at surgery and worse outcome when compared with the first generation.

\section{Familial Risk in FNMTC}

Considering these findings, NMTC does appear to be an inherited trait. The prevalence of FNMTC has been estimated to be between $2.5 \%$ and $8 \%$ of the total NMTC patients. The majority of FNMTC pedigrees are small [20]; the pattern of inheritance is usually autosomal dominant, but since a large number of pedigrees present a significant lack of penetrance, polygenic inheritance cannot be ruled out $[20,24]$. The variable expression of FNMTC suggests that the responsible gene(s) may lead to predisposition or susceptibility to thyroid cancer. In addition to NMTC, members of FNMTC pedigrees may present a spectrum of benign thyroid diseases including follicular adenoma, diffuse and multinodular goitre, and autoimmume thyroiditis. As mentioned above, these diseases are considerably more common in the general population than NMTC. However, the high occurrence of these diseases in FNMTC pedigrees suggests that they are a part of FNMTC, and pedigree members are therefore considered to be at increased risk of benign thyroid disease $[18,23]$.

\section{FNMTC Susceptibility Loci}

In order to identify the gene(s) responsible for thyroid cancer predisposition, several groups have undertaken genome wide linkage analysis using microsatellite markers evenly distributed across the genome and informative large pedigrees with multiple affected members. To date, four different loci have been identified for genetic predisposition to familial NMTC. The first locus to be implicated in familial PTC was MNG1, which maps to chromosome $14 \mathrm{q} 31$. In this case, the authors studied a family from Montreal, Canada, with 18 affected with multinodular goitre (MNG), two of whom presented with PTC and one with follicular adenoma. The predisposing locus was identified by linkage analysis with a maximal LOD (Logarithm Of Odds, a genetic measure of the significance of linkage) score of 4.88 distal to marker $\mathrm{D} 14 \mathrm{~S} 1030$, the region of interest spanning around $1 \mathrm{Mb}$ [25]. The locus was confirmed in other families with MNG [26], but no evidence of linkage was found in additional FNMTC pedigrees suggesting that only a small percentage of FNMTC can be attributed to this locus [20,27]. A second locus, PRN1, was identified by Malchoff et al. on chromosome 1q21 in an American family with five members affected by PTC, one by colon cancer and two by papillary renal carcinoma [28]. The susceptibility locus was identified at $1 \mathrm{q} 21$ with a maximum LOD score of 3.58 in a critical region of $20 \mathrm{cM}$ This region encompasses the NTRK1 gene, but no mutation segregating with the disease was found among FNMTC pedigrees [27]. To date, linkage to this locus has not been confirmed in any other independent study. The existence of a susceptibility locus for familial NMTC (NMTC1) on chromosome 2q21 was first identified in a large Tasmanian pedigree with recurrence of papillary thyroid 
carcinoma (PTC) [29]. In the same study, linkage analysis of 80 FNMTC pedigrees gave a significant LOD score of 3.07 at marker D2S2271. Stratification based on the presence of at least one case of the follicular variant of PTC, the phenotype observed in the Tasmanian family increased the corresponding LOD score for chromosome 2, suggesting that this locus may be strictly correlated to the follicular variant of PTC. Finally, the fourth susceptibility locus is TCO (Thyroid Carcinoma with Cell Oxyphilia) mapped on chromosome 19p13.2 by Canzian et al. [30]. The study analysed a large French pedigree with six patients affected by MNG and three by PTC. A review of the histology indicated that all cases examined presented oncocytic features. Oncocytic tumors, also known as oxyphilic tumors and in the thyroid gland as Hürthle cell tumors, are made of cells replete with mitochondria with a "swollen" (i.e., "oncocytic," from the Greek word onkoustai, to swell) appearance. Oncocytic tumors may occur at various sites (see [31], for a review) but they are more frequently observed in the thyroid gland. Thyroid oncocytic tumors originate from follicular cells, with the exception of the rare oncocytic variant of medullary carcinoma. They can be benign (oncocytic adenomas) or malignant (oncocytic carcinomas). Oncocytic tumors in the thyroid are regarded as special subtypes, since their features are distinct enough to set them apart from corresponding neoplasms lacking mitochondrial accumulation. Accordingly, oncocytic thyroid carcinomas are classified as variants of FTC (more commonly) or of PTC (less commonly) [1]. Using this distinctive phenotype for data analysis led to the successful identification of a predisposing locus for thyroid cancer with oncocytic features on chromosome 19p13.2, with a significant LOD score at marker D19S916 (3.01). The TCO locus extends up to $\sim 2 \mathrm{Mb}$ and has been further refined to a $1.6 \mathrm{Mb}$ interval by adding more markers and more families with affected individuals showing oncocytic tumors [32]. It is worth noting that linkage to the TCO locus has been subsequently confirmed in independent studies $[18,27]$. Furthermore, analysis of additional families has provided evidence for the genetic interaction between the TCO at 19p13 and NMTC1 at 2q21 loci, resulting in a significantly increased risk of NMTC in patients that carry both susceptibility loci [32]. Several groups have undertaken a positional candidate gene approach to identify the causative mutation underlying TCO predisposition, taking into account the specific phenotype of thyroid oncocytic tumors, that is, the abnormal proliferation of mitochondria and the presence of a severe bioenergetic defect [33-37]. Our group recently defined the bioenergetic defect in vitro in the only existing thyroid oncocytic tumor cell model, the XTC.UC1 cell line. Two mutations were identified in mitochondrial DNA (mtDNA) which affect complex I and III of the OXPHOS respiratory chain [38]. One of the mutations is a single base pair insertion in the ND1 complex I gene, causing a premature stop codon and the absence of the protein as evaluated by western blot analysis. The second is a missense mutation in the CYTB complex III gene. These two mutations markedly decrease the activity of both respiratory complexes and explain the defective ATP synthesis previously reported $[33,34]$. Subsequently, the high occurrence of pathogenic mutations impairing complex I has been confirmed by our group in vivo in sporadic thyroid oncocytic tumors, leading to the conclusion that disruptive complex I mutations may well be considered to be the hallmarks of the oncocytic phenotype [39]. The close association between disruptive complex I mutations and the oncocytic phenotype has also been confirmed in other types of oncocytic tumors [40-43]. Since the human complex I is composed of 45 subunits, only 7 of which are mtDNAencoded, our search for the defective nuclear gene on chromosome 19p13.2 began with the analysis of genes encoding mitochondrial complex I subunits and mapping to the TCO locus. So far, somatic and germline missense mutations have been reported in the NDUFA13 gene (previously known as GRIM19) [44], a member of complex I and a key regulator of cell death. Germline mutations have been reported by our group in TIMM44, a component of the mitochondrial translocon complex for importing nuclear-encoded proteins into the mitochondria [45]. However, the effect of these mutations in TCO predisposition is still uncertain, since either no functional studies have been presented (at least for NDUFA13) or they did not reveal a clear negative effect in functional molecular studies [45]. Moreover, the family in which the locus was originally mapped [30] did not carry any coding mutation in NDUFA13 and TIMM44, suggesting either that these genes are not directly involved in the TCO etiology or at least the presence of genetic heterogeneity in TCO. Several other genes mapping to the region encode proteins involved in mitochondrial functions and/or with a known role in tumor development, and these have been subsequently screened. A list of all the genes so far analysed without identifying etiological variants is reported in Table 2 (our unpublished results). Thus, the search for the TCO predisposing variants is still open. The application of nextgeneration sequencing technologies capable of sequencing of $\sim 2$ megabases of genomic DNA in a single experiment, will allow the entire TCO region to be resequenced, and not just the coding region of genes, a limit of the traditional candidate gene approach. Identification of the relevant mutation(s) will surely benefit the characterization of TCO.

\section{Association Studies in Thyroid Cancer}

FNMTC has been identified as a clinically distinct entity from its sporadic counterpart, and although the mutated genes(s) have not yet been identified, the genetic basis underlying its predisposition has been recognized by the scientific community. However, several studies have recently reported the identification of predisposing common variants in association-based case-control studies using single nucleotide polymorphism (SNP) high throughput genotyping [46-49]. One of the most significant studies was a genome-wide association scan in a large cohort of Icelandic cases with thyroid cancer and respective controls, followed by a replication study in individuals of European descent [49]. The authors demonstrated that two common variants, located on 9 q22.33 and $14 q 13.3$, are associated with the disease. Overall, the strongest association signals were observed for $\mathrm{rs} 965513$ on $9 \mathrm{q} 22.33\left(\mathrm{OR}=1.75 ; P=1.7 \times 10^{-27}\right)$ 
TABLE 2: New changes in cDNA of TCO candidate genes on 19p13.2.

\begin{tabular}{|c|c|c|c|c|}
\hline PCR product & Change in cDNA & $\begin{array}{c}\text { Type of aa } \\
\text { change }\end{array}$ & $\begin{array}{l}\text { Het frequency in } \\
\text { TCO patients }(\%)\end{array}$ & $\begin{array}{l}\text { Het frequency in } \\
\text { controls }(\%)\end{array}$ \\
\hline TIMM44x4 & G344A C925A & silent P308Q & 12.512 .5 & na 00 na na \\
\hline TIMM44x9 & G1274A G509A & silent silent & 12.512 .5 & na na 22.53 .0 \\
\hline TIMM44x13 & T971C G868T & silent 3'UTR & 12.512 .58 .0 & na na na na \\
\hline ELAVL1x3 & C591A G1111C & silent R219P & 42.913 .025 .014 .2 & na na na na \\
\hline ELAVL1x5 & $\Delta$ (СТTCСАCTTCA & 3'UTR 5'UTR & 12.512 .5 & na na na na \\
\hline CCL25x5 & AC) bp1267-1280 & $\mathrm{T} 289 \mathrm{M}$ & 37.550 .037 .550 .0 & na na 7.3 na na \\
\hline LASS1x3 & C182T A866T & $\mathrm{K} 1266 \mathrm{~N}$ & 37.537 .5 & \\
\hline MARCH2x5 & A3798C C4996T & silent Y1897D & 37.512 .537 .537 .5 & \\
\hline$M A R C H 2 \times 5$ & T5692G G9569C & S3189T & 12.550 .0 & \\
\hline GRIM19x1 & A21814G T21858A & I7271V silent & 12.5 & \\
\hline$E D G 5 \times 2$ & G26790A C25572T & silent silent & & \\
\hline MUC16x1 & T25638G A27791C & D8546E & & \\
\hline MUC16x1 & C31905T G31721A & N9263T & & \\
\hline MUC16x1 & G36955A G39400A & silent R10573H & & \\
\hline MUC16x2 & $\mathrm{C} 41705 \mathrm{~T}$ & E12318L & & \\
\hline MUC16x3 & & V13133M & & \\
\hline MUC163x & & P13901L & & \\
\hline \multicolumn{5}{|l|}{ MUC16×3 } \\
\hline \multicolumn{5}{|l|}{ MUC16x3 } \\
\hline \multicolumn{5}{|l|}{$M U C 16 \times 3$} \\
\hline \multicolumn{5}{|l|}{ MUC16x3 } \\
\hline \multicolumn{5}{|l|}{ MUC16x5 } \\
\hline \multicolumn{5}{|l|}{ MUC16x5 } \\
\hline \multicolumn{5}{|l|}{ MUC16x15 } \\
\hline \multicolumn{5}{|l|}{ MUC16×39 } \\
\hline MUC16x63 & & & & \\
\hline
\end{tabular}

na $=$ not available. The changes cosegregating are reported. Only for TIMM44 missense change, the variant was not found in a large group of controls. The other genes screened so far but with no new changes identified are NDUFA7, PPAN, FBLX12, ICAM1, ICAM4, LASS1, LASS4, SMARCA4, DNM2, and ANGPL4; RAB11B; ADAMTS10; PIN1; UBL5; and KEAP1.

and rs944289 on $14 \mathrm{q} 13.3\left(\mathrm{OR}=1.37 ; P=2.0 \times 10^{-9}\right)$. The gene closest to the 9q22.33 locus is FOXE1 (TTF2), and NKX2-1 (TTF1) is among the genes located at the 14q13.3 locus. Both variants contributed to an increased risk of both papillary and follicular thyroid cancer. Approximately $3.7 \%$ of individuals were homozygous for both variants, and their estimated risk of thyroid cancer was 5.7-fold greater than that of noncarriers. In a study using a large sample set from the general population, both risk alleles are associated with low concentrations of thyroid stimulating hormone (TSH), and the $9 \mathrm{q} 22.33$ allele was associated with low concentration of thyroxin $(\mathrm{T}(4))$ and high concentration of triiodothyronine (T(3)). Another interesting study, although not specific for thyroid cancer as such, in an isolated population of Sardinians identified a strong association $\left(P=1.3 \times 10^{-11}\right)$ between rs4704397 and circulating TSH levels [48]. Serum TSH is a sensitive indicator of thyroid function, and overt abnormalities in thyroid function lead to common endocrine disorders. Each additional copy of the minor A allele was associated with an increase in TSH. The marker is located in intron 1 of $P D E 8 B$, encoding a high-affinity cAMP-specific phosphodiesterase. The association was replicated in genetically distant cohorts from Tuscany and Old Order Amish $\left(\right.$ overall $P$ value $\left.=1.9 \times 10^{-20}\right)$. It will be very interesting to analyse the association of the above-mentioned SNPs with the familial form of non-medullary thyroid carcinoma.

\section{Conclusions}

Familial NMTC represents 3\%-7\% of all thyroid tumors and is associated with some of the highest familial risks among all cancers, with a risk of developing this type of neoplasia for first-degree relatives of 5-10-fold compared to the general population. Several predisposing loci have been identified in the recent years but the mutated gene has not been identified yet. However, the new technologies already available have rendered the resequencing of large genomic regions from defined linkage intervals reasonably possible in single experiments, and the application of these methods will greatly speed up the search for the NMTC gene(s). It will then become possible for NMTC families to receive careful genetic counseling for all at-risk members similarly to what 
is already happening for FMTC. In addition, the study of FNMTC genetics, and in particular familial TCO represents a key model for the study of nuclear and mitochondrial crosstalk in thyroid tumor development. The thyroid gland is characterized by a high energetic metabolism and any genetic defect (either of nuclear or mitochondrial origin) leading to bioenergetic deficits may lead to an alteration of this crosstalk and to an alteration of the mitochondrial phenotype, as seen in TCO. Identifying the causative mutations involved in these energetic defects will also provide a powerful tool to design new and specific treatments for such tumors.

\section{Acknowledgment}

The authors are grateful to Professor K. Rodhen for helpful suggestions and critical reading.

\section{References}

[1] World Health Organization, Classification of Tumors-Pathology and Genetics, IARC Press, Lyon, France, 2004.

[2] W. Van Veelen, J. W. B. De Groot, D. S. Acton, et al., "Medullary thyroid carcinoma and biomarkers: past, present and future," Journal of Internal Medicine, vol. 266, no. 1, pp. 126-140, 2009.

[3] E. Negri, C. La Vecchia, S. Franceschi, and F. Levi, "Patterns of mortality from major cancers in Europe," Cancer Epidemiology Biomarkers and Prevention, vol. 3, no. 7, pp. 531-536, 1994.

[4] V. Nosé, "Familial non-medullary thyroid carcinoma: an update," Endocrine Pathology, vol. 19, no. 4, pp. 226-240, 2008.

[5] J. R. Burgess, T. Dwyer, K. McArdle, P. Tucker, and D. Shugg, "The changing incidence and spectrum of thyroid carcinoma in Tasmania (1978-1998) during a transition from iodine sufficiency to iodine deficiency," Journal of Clinical Endocrinology and Metabolism, vol. 85, no. 4, pp. 1513-1517, 2000.

[6] T. Pal, F. D. Vogl, P. O. Chappuis, et al., "Increased risk for nonmedullary thyroid cancer in the first degree relatives of prevalent cases of nonmedullary thyroid cancer: a hospitalbased study," Journal of Clinical Endocrinology and Metabolism, vol. 86, no. 11, pp. 5307-5312, 2001.

[7] H. R. Harach, K. O. Franssila, and V.-M. Wasenius, "Occult papillary carcinoma of the thyroid. A "normal" finding in Finland. A systematic autopsy study," Cancer, vol. 56, no. 3, pp. 531-538, 1985.

[8] R. Ciampi and Y. E. Nikiforov, "Minireview: RET/PTC rearrangements and braf mutations in thyroid tumorigenesis," Endocrinology, vol. 148, no. 3, pp. 936-941, 2007.

[9] M. A. Pierotti and A. Greco, "Oncogenic rearrangements of the NTRK1/NGF receptor," Cancer Letters, vol. 232, no. 1, pp. 90-98, 2006.

[10] P. Hou, D. Liu, Y. Shan, et al., "Genetic alterations and their relationship in the phosphatidylinositol 3-kinase/Akt pathway in thyroid cancer," Clinical Cancer Research, vol. 13, no. 4, pp. 1161-1170, 2007.

[11] T. Fukushima and S. Takenoshita, "Roles of RAS and BRAF mutations in thyroid carcinogenesis," Fukushima Journal of Medical Science, vol. 51, no. 2, pp. 67-75, 2005.

[12] H. V. Reddi, B. McIver, S. K. G. Grebe, and N. L. Eberhardt, "The paired box-8/peroxisome proliferator-activated receptor- $\gamma$ oncogene in thyroid tumorigenesis," Endocrinology, vol. 148, no. 3, pp. 932-935, 2007.
[13] Y. E. Nikiforov, "Genetic alterations involved in the transition from well-differentiated to poorly differentiated and anaplastic thyroid carcinomas," Endocrine Pathology, vol. 15, no. 4, pp. 319-327, 2004.

[14] M. L. Richards, "Thyroid cancer genetics: multiple endocrine neoplasia type 2, nonmedullary familial thyroid cancer, and familial syndromes associated with thyroid cancer," Surgical Oncology Clinics of North America, vol. 18, no. 1, pp. 39-52, 2009.

[15] M. Capezzone, S. Marchisotta, S. Cantara, et al., "Familial non-medullary thyroid carcinoma displays the features of clinical anticipation suggestive of a distinct biological entity," Endocrine-Related Cancer, vol. 15, no. 4, pp. 1075-1081, 2008.

[16] D. E. Goldgar, D. F. Easton, L. A. Cannon-Albright, and M. H. Skolnick, "Systematic population-based assessment of cancer risk in first-degree relatives of cancer probands," Journal of the National Cancer Institute, vol. 86, no. 21, pp. 1600-1608, 1994.

[17] K. Hemminki, R. Rawal, B. Chen, and J. L. Bermejo, "Genetic epidemiology of cancer: from families to heritable genes," International Journal of Cancer, vol. 111, no. 6, pp. 944-950, 2004.

[18] O. Alsanea and O. H. Clark, "Familial thyroid cancer," Current Opinion in Oncology, vol. 13, no. 1, pp. 44-51, 2001.

[19] D. W. Robinson and T. G. Orr, "Carcinoma of the thyroid and other diseases of the thyroid in identical twins," Archives of Surgery, vol. 70, no. 6, pp. 923-928, 1955.

[20] F. Lesueur, M. Stark, T. Tocco, et al., "Genetic heterogeneity in familial nonmedullary thyroid carcinoma: exclusion of linkage to RET, MNG1, and TCO in 56 families," Journal of Clinical Endocrinology and Metabolism, vol. 84, no. 6, pp. 2157-2162, 1999.

[21] C. D. Malchoff, M. Sarfarazi, B. Tendler, F. Forouhar, G. Whalen, and D. M. Malchoff, "Familial papillary thyroid carcinoma is genetically distinct from familial adenomatous polyposis coli," Thyroid, vol. 9, no. 3, pp. 247-252, 1999.

[22] L. Frich, E. Glattre, and L. A. Akslen, "Familial occurrence of nonmedullary thyroid cancer: a population-based study of 5673 first-degree relatives of thyroid cancer patients from Norway," Cancer Epidemiology Biomarkers and Prevention, vol. 10, no. 2, pp. 113-117, 2001.

[23] C. D. Malchoff and D. M. Malchoff, "Familial nonmedullary thyroid carcinoma," Cancer Control, vol. 13, no. 2, pp. 106$110,2006$.

[24] J. R. Burgess, A. Duffield, S. J. Wilkinson, et al., "Two families with an autosomal dominant inheritance pattern for papillary carcinoma of the thyroid," Journal of Clinical Endocrinology and Metabolism, vol. 82, no. 2, pp. 345-348, 1997.

[25] G. R. Bignell, F. Canzian, M. Shayeghi, et al., "Familial nontoxic multinodular thyroid goiter locus maps to chromosome $14 \mathrm{q}$ but does not account for familial nonmedullary thyroid cancer," American Journal of Human Genetics, vol. 61, no. 5, pp. 1123-1130, 1997.

[26] S. Neumann, H. Willgerodt, F. Ackermann, et al., "Linkage of familial euthyroid goiter to the multinodular goiter-1 locus and exclusion of the candidate genes thyroglobulin, thyroperoxidase, and $\mathrm{Na}^{+} / \mathrm{I}^{-}$symporter," Journal of Clinical Endocrinology and Metabolism, vol. 84, no. 10, pp. 3750-3756, 1999.

[27] S. Bevan, T. Pal, C. R. Greenberg, et al., "A comprehensive analysis of MNG1, TCO1, fPTC, PTEN, TSHR, and TRKA in familial nonmedullary thyroid cancer: confirmation of linkage to TCO1," Journal of Clinical Endocrinology and Metabolism, vol. 86, no. 8, pp. 3701-3704, 2001. 
[28] C. D. Malchoff, M. Sarfarazi, B. Tendler, et al., "Papillary thyroid carcinoma associated with papillary renal neoplasia: genetic linkage analysis of a distinct heritable tumor syndrome," Journal of Clinical Endocrinology and Metabolism, vol. 85, no. 5, pp. 1758-1764, 2000.

[29] J. D. McKay, F. Lesueur, L. Jonard, et al., "Localization of a susceptibility gene for familial nonmedullary thyroid carcinoma to chromosome 2q21," American Journal of Human Genetics, vol. 69, no. 2, pp. 440-446, 2001.

[30] F. Canzian, P. Amati, H. R. Harach, et al., "A gene predisposing to familial thyroid tumors with cell oxyphilia maps to chromosome 19p13.2," American Journal of Human Genetics, vol. 63, no. 6, pp. 1743-1748, 1998.

[31] G. Tallini, "Oncocytic tumours," Virchows Archiv, vol. 433, no. 1, pp. 5-12, 1998.

[32] J. D. McKay, D. Thompson, F. Lesueur, et al., "Evidence for interaction between the TCO and NMTC1 loci in familial non-medullary thyroid cancer," Journal of Medical Genetics, vol. 41, no. 6, pp. 407-412, 2004.

[33] F. Savagner, A. Chevrollier, D. Loiseau, et al., "Mitochondrial activity in XTC.UC1 cells derived from thyroid oncocytoma," Thyroid, vol. 11, no. 4, pp. 327-333, 2001.

[34] F. Savagner, B. Franc, S. Guyetant, P. Rodien, P. Reynier, and Y. Malthiery, "Defective mitochondrial ATP synthesis in oxyphilic thyroid tumors," Journal of Clinical Endocrinology and Metabolism, vol. 86, no. 10, pp. 4920-4925, 2001.

[35] F. Savagner, D. Mirebeau, C. Jacques, et al., "PGC-1-related coactivator and targets are upregulated in thyroid oncocytoma," Biochemical and Biophysical Research Communications, vol. 310, no. 3, pp. 779-784, 2003.

[36] O. Baris, F. Savagner, V. Nasser, et al., “Transcriptional profiling reveals coordinated up-regulation of oxidative metabolism genes in thyroid oncocytic tumors," Journal of Clinical Endocrinology and Metabolism, vol. 89, no. 2, pp. 994-1005, 2004.

[37] O. Baris, D. Mirebeau-Prunier, F. Savagner, et al., "Gene profiling reveals specific oncogenic mechanisms and signaling pathways in oncocytic and papillary thyroid carcinoma," Oncogene, vol. 24, no. 25, pp. 4155-4161, 2005.

[38] E. Bonora, A. M. Porcelli, G. Gasparre, et al., "Defective oxidative phosphorylation in thyroid oncocytic carcinoma is associated with pathogenic mitochondrial DNA mutations affecting complexes I and III," Cancer Research, vol. 66, no. 12, pp. 6087-6096, 2006.

[39] G. Gasparre, A. M. Porcelli, E. Bonora, et al., "Disruptive mitochondrial DNA mutations in complex I subunits are markers of oncocytic phenotype in thyroid tumors," Proceedings of the National Academy of Sciences of the United States of America, vol. 104, no. 21, pp. 9001-9006, 2007.

[40] J. Costa-Guda, T. Tokura, S. I. Roth, and A. Arnold, "Mitochondrial DNA mutations in oxyphilic and chief cell parathyroid adenomas," BMC Endocrine Disorders, vol. 7, article 8, 2007.

[41] G. Gasparre, E. Hervouet, E. de Laplanche, et al., "Clonal expansion of mutated mitochondrial DNA is associated with tumor formation and complex I deficiency in the benign renal oncocytoma," Human Molecular Genetics, vol. 17, no. 7, pp. 986-995, 2008.

[42] G. Gasparre, L. Iommarini, A. M. Porcelli, et al., "An inherited mitochondrial DNA disruptive mutation shifts to homoplasmy in oncocytic tumor cells," Human Mutation, vol. 30, no. 3, pp. 391-396, 2009.
[43] F. A. Zimmermann, J. A. Mayr, D. Neureiter, et al., "Lack of complex i is associated with oncocytic thyroid tumours," British Journal of Cancer, vol. 100, no. 9, pp. 1434-1437, 2009.

[44] V. Máximo, T. Botelho, J. Capela, et al., "Somatic and germline mutation in GRIM-19, a dual function gene involved in mitochondrial metabolism and cell death, is linked to mitochondrion-rich (Hürthle cell) tumours of the thyroid," British Journal of Cancer, vol. 92, no. 10, pp. 1892-1898, 2005.

[45] E. Bonora, C. Evangelisti, F. Bonichon, G. Tallini, and G. Romeo, "Novel germline variants identified in the inner mitochondrial membrane transporter TIMM44 and their role in predisposition to oncocytic thyroid carcinomas," British Journal of Cancer, vol. 95, no. 11, pp. 1529-1536, 2006.

[46] K. Jazdzewski, E. L. Murray, K. Franssila, B. Jarzab, D. R. Schoenberg, and A. de la Chapelle, "Common SNP in premiR-146a decreases mature miR expression and predisposes to papillary thyroid carcinoma," Proceedings of the National Academy of Sciences of the United States of America, vol. 105, no. 20, pp. 7269-7274, 2008.

[47] H. He, R. Nagy, S. Liyanarachchi, et al., "A susceptibility locus for papillary thyroid carcinoma on chromosome 8q24," Cancer Research, vol. 69, no. 2, pp. 625-631, 2009.

[48] L. Arnaud-Lopez, G. Usala, G. Ceresini, et al., "Phosphodiesterase $8 \mathrm{~B}$ gene variants are associated with serum TSH levels and thyroid function," American Journal of Human Genetics, vol. 82, no. 6, pp. 1270-1280, 2008.

[49] J. Gudmundsson, P. Sulem, D. F. Gudbjartsson, et al., "Common variants on 9 q22.33 and $14 \mathrm{q} 13.3$ predispose to thyroid cancer in European populations," Nature Genetics, vol. 41, no. 4, pp. 460-464, 2009. 


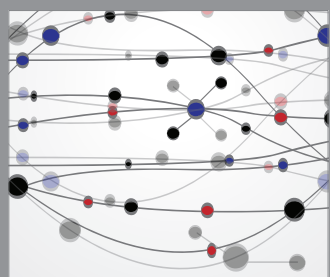

The Scientific World Journal
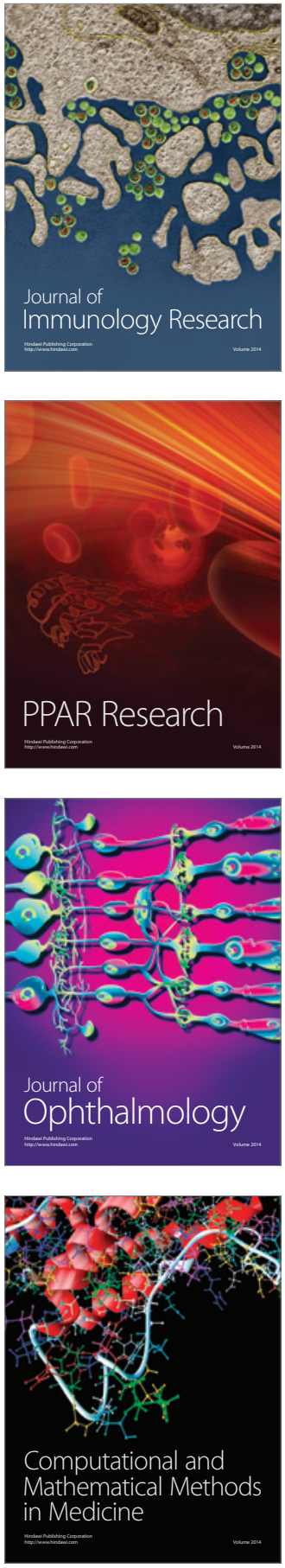

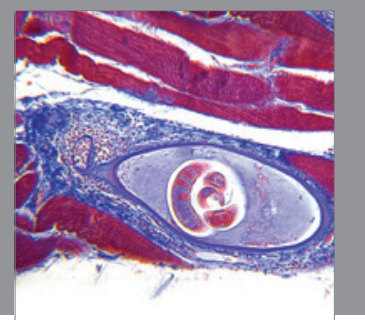

Gastroenterology

Research and Practice
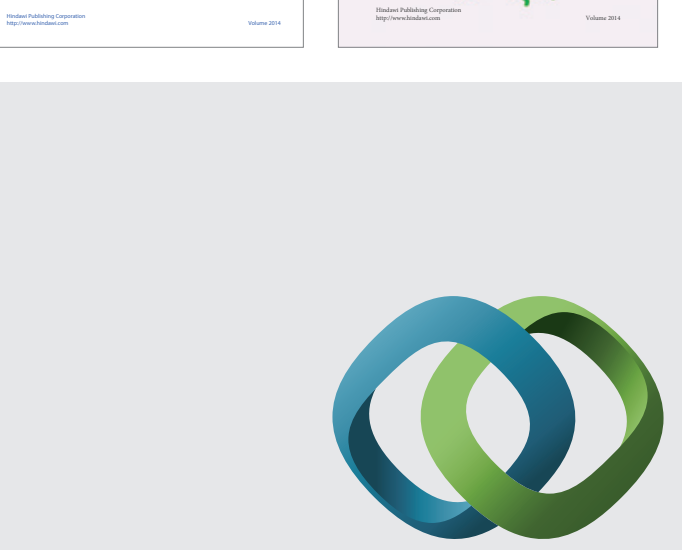

\section{Hindawi}

Submit your manuscripts at

http://www.hindawi.com
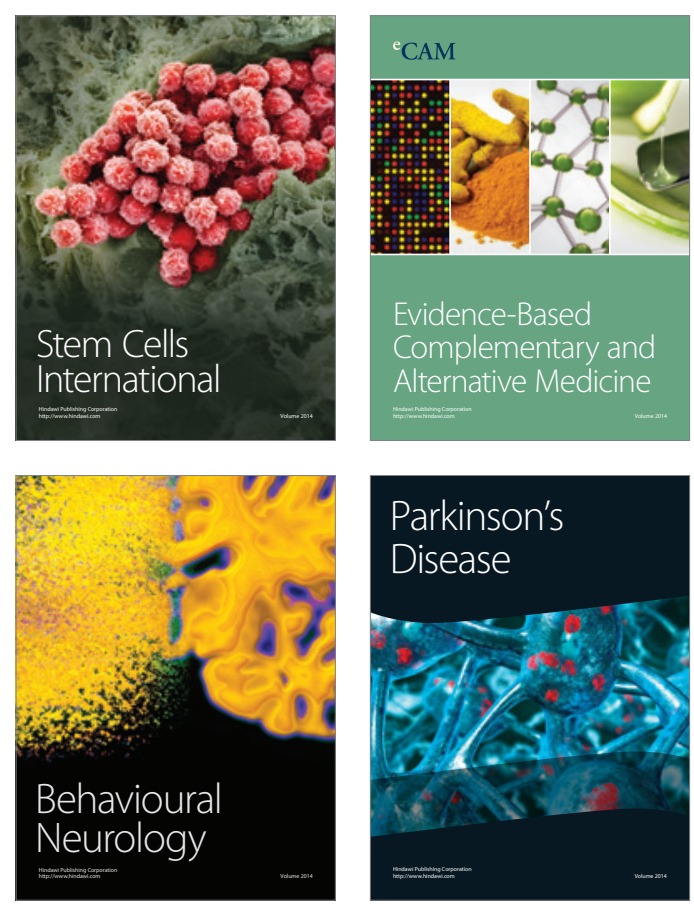

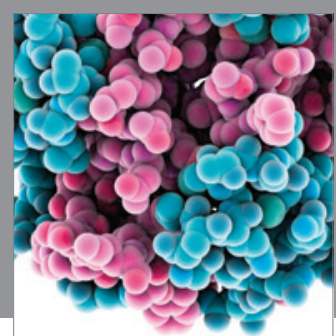

Journal of
Diabetes Research

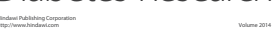

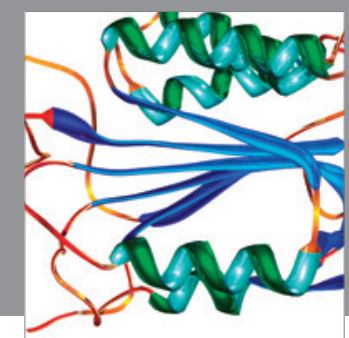

Disease Markers
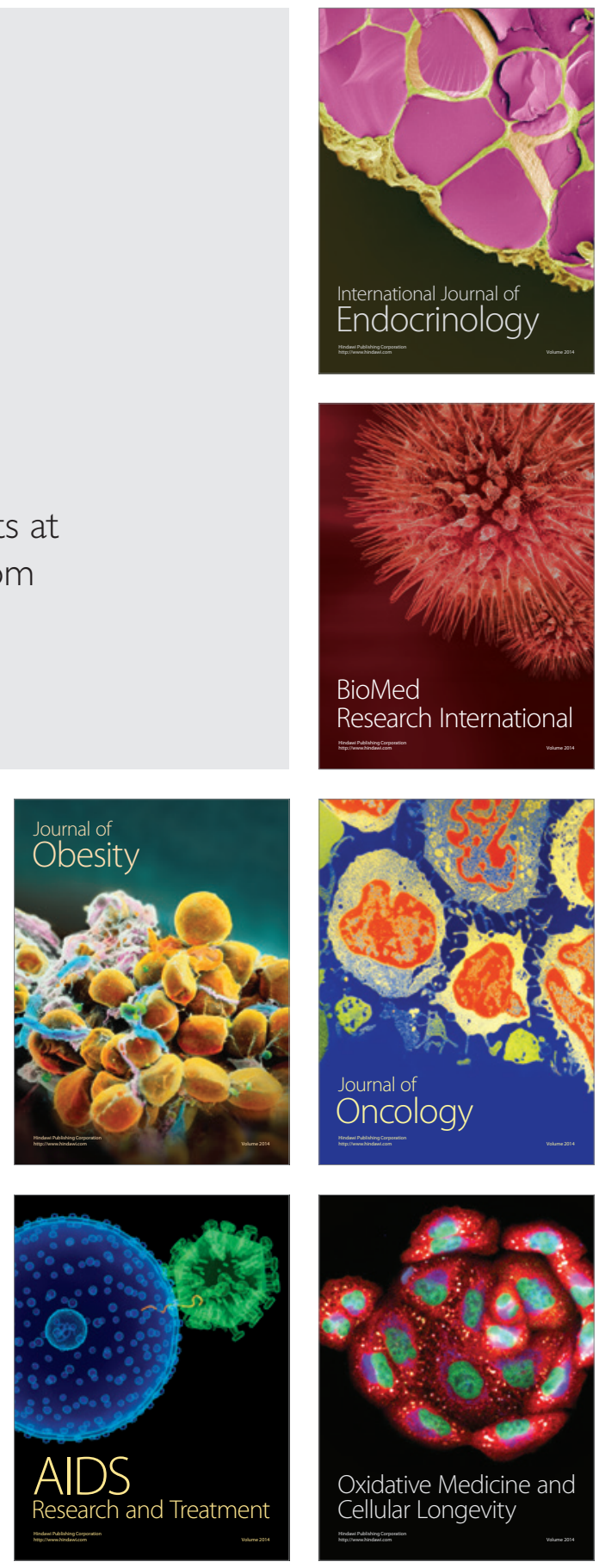